\title{
Towards a Customer-Driven Value Chain Framework - A Set-Based Oriented Approach
}

\author{
João Bastos ${ }^{1,2}$, Américo Azevedo ${ }^{1}$, Paulo Ávila ${ }^{2}$, \\ ${ }^{1}$ INESC TEC - INESC Technology and Science and FEUP - Faculty of Engineering, \\ University of Porto \\ Campus da FEUP, Rua Dr Roberto Frias, 4200-465 Porto, Portugal \\ ${ }^{2}$ ISEP/IPP - School of Engineering, Polytechnic Institute of Porto \\ Rua Dr. António Bernardino de Almeida, 431, 4249-015 Porto, Portugal \\ \{jsbastos, ala\}@fe.up.pt; psa@isep.ipp.pt
}

\begin{abstract}
In today's business, consumers are challenging manufacturers by increasingly demanding low volumes of innovative, fashionable and inexpensive products; adopting high quality standards; responding in smaller intervals of time, and with high configurability and parameterization. This omnipresent scenario poses challenging opportunities for collaborative networked organizations. The present paper addresses the main collaborative business processes tailored for responsiveness and efficient use of knowledge on customized manufacturing environments through a lean-based framework proposal for collaborative networks inspired in the Set-Based Concurrent Engineering (SBCE) methodology. In particular this work describes the ongoing implementation of the proposed concepts through a web-based collaborative portal.
\end{abstract}

Keywords: Collaborative Networks; Customer-Driven; Framework; Set-Based Design.

\section{Introduction}

The recent decades have shown at manufacturing level an expansion of collaborative strategies addressing the small batches to lot one production of highly-customized complex products. This is especially critical for innovative and/or fashionable products with short to micro life-cycles. In fact, consumer needs and expectations are arising as challenging opportunities for worldwide manufacturing companies which are required to put more emphasis on the service levels they provide, by reducing response times and by tackling customers' specific demand needs of small series of innovative/fashionable inexpensive high quality products, in shorter periods of time.

Facing a competitive market, companies' managers are constantly challenged to reduce the lead time between technical or market opportunity arising and satisfying the customer need with full-rate production of a quality product. The time to market on the case of innovative and fashionable goods is a critical factor, since all competitors get access to new technical ideas and new market information at about the same time. 
One other hand, with the increasing empowerment of the user/customer role, the design focus has been shifting from a designer-centered approach to a co-designing attitude in which the roles of the designer, the researcher and the 'customer' have been moving increasingly closer. The implications of this shift for traditional manufacturing networks are enormous. The current evolution in the design approach has a significant impact in the product configurations, product volumes and response time, changing the landscape of collaborative networking.

In order to conceive, design, develop, manufacture and supply such products, new approaches and underneath supporting services for collaborative networking are increasingly mandatory in order to companies succeed in addressing the market demand through customer-driven value chains.

This paper addresses the multidisciplinary complexity of customer-driven value chains creation for innovative/fashionable products, in particular, by tackling the main collaborative business processes tailored for responsiveness and efficient use of knowledge on customized manufacturing environments through a lean-based framework proposal.

The proposed framework extends the lean product development principles followed by the Toyota Motor Corporation and presented by D. Sobek as Set-Based Concurrent Engineering (SBCE)[1] to the presently growing and increasingly significant environment of Collaborative Networks (CNs).

This innovative lean-based framework is intended to cope with the challenges posed by the omnipresent consumers demand of products with manufacturing of low volume, high variability and increasingly reduced time-to-market expectations.

The remaining sections of this paper are organized as follows: primary the existing related literature and research questions are presented as background and research topics, followed by the presentation of the set-based principles in collaborative networks. Afterwards, the customer-driven value chain framework is portrayed. Finally, conclusions and future developments are presented regarding the framework instantiation and further improvement.

\section{Background and Research Topics}

The acceleration of globalization and rapid technological evolution are leading to an increased unpredictability and instability. The emergence of global and competitive markets are forcing the companies, especially in the case of SMEs, to adjust to this new aggressive environment in order to proactively respond to challenging market requirements with increased responsiveness and flexibility [2].

This competitive reality is intensified by the fact that the demand of consumer goods, especially innovative and fashion products, have in the recent past forcing manufacturers into delivering an increased number of product variants with a dramatic reduction of products life-cycle. Furthermore, paradigms such as mass customization and personalization are forcing companies to increased flexibility in order to produce small batches, till one-of-a-kind product, to satisfy customer demand. 
In many industries, an ever growing number of new products (often only incremented modified) are introduced within increasingly shorter time intervals. In many cases, product life-cycles have been cut to one third or even one fourth over the past decades [3]. Briefly, the modern business landscape is characterized by small batches, short to micro product life-cycles, fast-passed new product releases designed to attend increasingly knowledgeable, well informed, and demanding customers.

All these issues create a challenge for companies' managers: how to address this present-day consumers' demand for personalized value-added products, but also cope with it in terms of high quality levels, innovative functionalities and responsiveness?

Certainly, align with the objective to address this new customer demand challenges, there is a pressing need of new methods and tools for manufacturing value chains supported in the collaborative network organizational paradigm [4]. This new forms of networked organizations present a promising approach to deal with the need to customer driven focus, reduced time to market of new products and cost effective manufacturing in a cooperative and collaborative environment.

\subsection{Customer-Driven Value Chains}

Nowadays competition within the innovative and fashionable goods sectors is between global networks and one of the critical matters are on how to put and execute innovative managerial models and methods to provide and sustain collaborative practices, especially among SMEs, which represents the majority of companies in Europe [5, 6].

The most recent research in the topic of supply networks addressed distinct forms of business organizations that participate in value creation. They are distinguished for example, by the degree of virtualization or hierarchical structure (hierarchical vs. nonhierarchical networks), the value chain orientation (horizontal, vertical, lateral) and life span (long-term vs. short-term) [7].

Research in collaborative networks of innovative and fashionable products have identified six key phases in order to organizations address a specific market need till final dispatch to the customer (see Fig. 1). It also have shown that each one of these phases present relevant challenges regarding their complexity, time constraints and resources consumption [8].

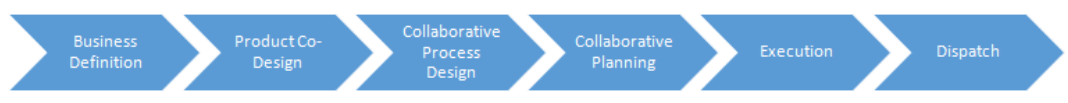

Fig. 1. Market oriented manufacturing network phases

In face of these critical impact phases, the prevailing market environment asks for flexible and reactive organizational structures which rapidly adjust to new manufacturing challenges and revise the business requirements accordingly. These new market characteristics are compelling manufacturing networks to embody shorter life-time existences and take advantage of new infrastructure technologies to support distributed decision making, information sharing and knowledge management [2]. 
In order to answer to the consumer's pressing needs and expectations, the paradigm of customer-driven value chains is emerging in literature as a collaborative approach [9-11]. Based on this new paradigm, new approaches to addressed and engage market demand are envisioned. These approaches are based not only on traditional sales distribution channels (as stores or sellers) but increasingly on an Internet mediated interaction with consumers covering aspects such as product codesign, product customization till final sale.

Exploratory work provided evidence to researchers that responsiveness is intrinsically related to competiveness. Namely, organizations can increase their ability to compete based on product innovation, low time to market, low price and high delivery dependability by increasing the firms' responsiveness [12].

A direct outcome of firms and by extension collaborative networks responsiveness is the reduction of the time to market. The time to market is the lead time between a technical or market opportunity arising and satisfying the customer need with full-rate production or quality product. The time to market lead time is critical since all competitors eventually get access to new technical ideas and new market information at about same time. The winner is the one which is consistently faster than competition. As Li et al. states: "time to market is the ability of an organization to introduce new products faster than major competitors"[13]. In reality there is a extensive acknowledgment that time to market is a fundamental determinant for competitive advantage [14].

According to Ward [15] the time to market can be decomposed into the sum of four periods: reaction time (period between the opportunity appearing and company decision to invest); exploration time (period which the development team explores alternative implementations); lock-in time (during which a final solution is detailed); and fix-up time (during which the company tries to deal with the problems aroused during the implementation of the solution) (see Fig. 2).

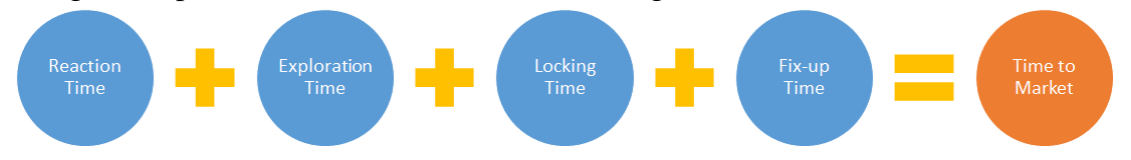

Fig. 2. Time to Market periods (based in [15]).

Inversely to the concept of 'time to market' there is the concept of 'market miss'. In reality, markets are missed because the development team fails to understand the customer, or because it is not innovative enough and therefore missing the customer needs on time or generating cost and quality problems [15].

Customarily, the development value stream inside companies or inside collaborative networks, produces operational value streams. Operational value streams run from suppliers to manufacturers, into product characteristics, and finally out to customers. Manufacturing units are the primary customers of the development value streams. Actuality, the development process only has value if it enables manufacturing operations to deliver better products to the final customer.

In conventional development processes the approach followed is the "waterfall" or "V" methodology. In this approach, starting from the concept specification, first it is designed the system, freezing the interfaces between the subsystems, then designed the subsystems, following a top down method. 


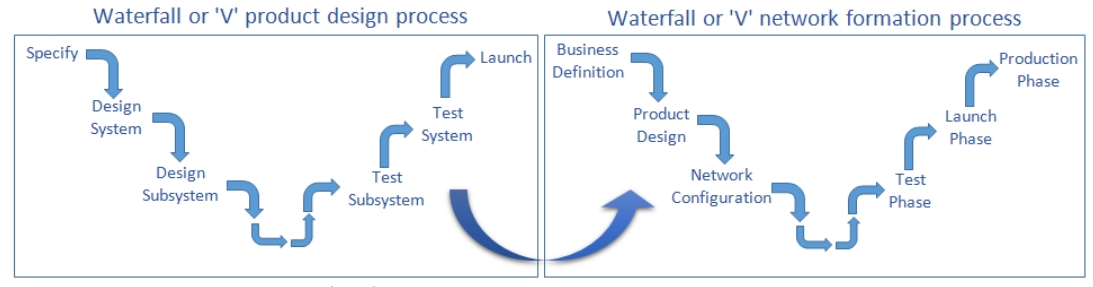

Fig. 3. Waterfall or traditional approach

A similar "waterfall" approach is followed in the development process of collaborative networks. The initial definition of the business opportunity leads to the collaborative design of the product and subsequently to the process planning and the network configuration definition. The Fig. 3 presents the similarities between the product design process and the collaborative network formation process using the conventional "waterfall" approach.

Although abundantly used this "waterfall" approach, it presents for several researchers significant drawbacks. The followed top down approach means that critical systems decisions about module or subsystems interfaces are made on the basis of early insufficient data about what is possible. The resulting designs on products, processes or network configuration are usually distorted and inconsistent, leading to usually low levels of reutilization of parts, manufacturing systems or reconfiguration of networks [16-18].

In reality, is common for companies select suppliers through a bid process usually based on cost. This approach requires the release of product specifications or drawings. In many cases, this practice blocks the opportunity to identify what suppliers and partners can actually do, and therefore which system design, module specification or network configuration actually makes sense. Also, since the selection of network members is based in many cases on the basis of quotation, which is in many cases, is more a "promise" than a commitment.

A major consequence of the typical product development cycle based on the "waterfall" approach in supply networks is the occurrence of problems that are discovered late or in advanced phases of the design process. These problems force design loopbacks and network reconfiguration (see Fig. 4) which often consumes 50 to $75 \%$ of engineering resources [19].

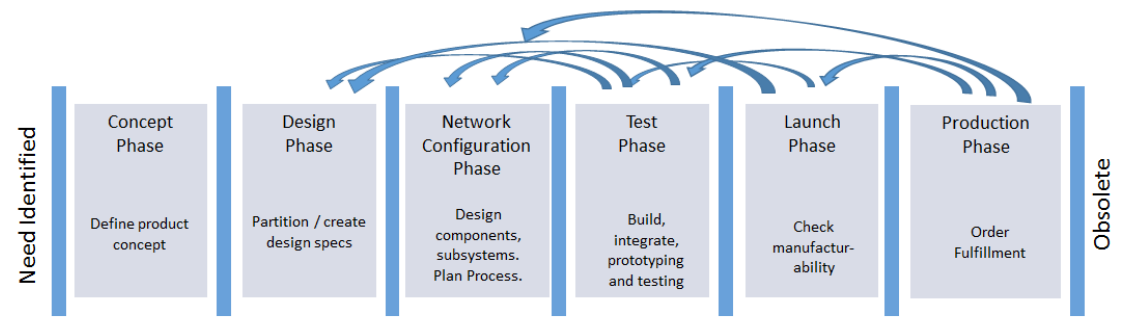

Fig. 4. Loopbacks in "waterfall" collaborative networks formation 
In summary, the traditional "waterfall" approach presents several drawbacks which include: inefficient use of resources due to the late problems discovery and the necessary loopbacks; the discard of knowledge due to the early product concept definition and design specifications which limits the network partners involvement and knowledge generation; and finally generates poor and unreliable solutions in terms of products and network configurations since it is based before the customer interests are understood.

\subsection{Collaborative Issues}

The recent past has shown an extraordinary expansion in collaborative networks and customer communities, especially due to the advances in ICT technologies, namely the internet support and social networking. Manufacturers, designers and customers are coming together in online communities, where they publish and share their products and services experiences, assessing the manufactures, vendors and service providers effectiveness [20]. Increasingly, consumers are participating both in the front-end period with contributions to the idea generation and conceptualization, and the back-end period with involvement in the sketch, design and testing phases of new product development by enhancing the innovation process and thus co-creating value [21].

Simultaneously, due to the business increasing emphasis on technological innovation and the improvements in ICT technologies, a growing number of designers and network stakeholders use knowledge management tools and integrated systems to support innovation in collaborative design [22].

The recent research shows that collaborative design is a knowledge-based path, requiring not only experts with knowledge and experience on different multidisciplinary areas, but also requiring the integration and coordination of the design and development phases of different actors. The challenge of providing reliable and fully operational collaborative design and knowledge management systems increasingly relies in integrated platforms but also practices and methods that promote and sustain the development coordinately [23].

\section{Set-Based Approach in Collaborative Networks}

The concept of set based thinking was initially conceived by researchers from MIT and University of Michigan in the late 90's. Starting from Toyota's product development success practices, Allen Ward and is team developed what they latter labeled as SBCE (Set-Based Concurrent Engineering). From the field analysis conducted from D. Sobek simultaneously at Toyota Motor Company and Chrysler, it was evident that Toyota's product development practices surpass its competitors. Toyota is an industry leader in product development lead time and new product launches, while using fewer resources than its competitors. It has also shown consistent market share growth and profit per vehicle. Toyota never performs unplanned design loopbacks; had a systematic knowledge sharing across projects; 
achieve $80 \%$ engineering development value-added productivity ( 4 times the typical automobile manufacturer); and never misses its milestones dates [24, 25].

Sobek summarized the definition of SBCE as engineers and product designers "reasoning, developing, and communicating about sets of solutions in parallel and relatively independent" [1]. In fact, according to the lean approach from Toyota, the most important input to production is knowledge. Starting from this paradigm, Toyota doesn't understood product development as a series of steps that result in a final product, but rather as an inclusive environment that yield a stream of products.

In order to acquire this 'knowledge breeding environment', the set-based approach followed by Toyota seeks continuously to obtain usable knowledge from the following sources:

- Integration knowledge - includes learning about customers, suppliers, partners, designers, the manufacturing network, the market;

- Innovation knowledge - the conception of new ideas and solutions;

- Feasibility knowledge - allows comprehension of the manufacturing constraints and capabilities enabling better decisions among the possible solutions.

The effort to collect this knowledge starts immediately at the customer requirements early definition. Traditionally, using the "waterfall" approach, the customer requirements are frozen early, followed by a more detailed design and interface specification of the process. In contrast, in the set-based approach, Toyota builds a set of possibilities to satisfy their customer needs, and through a series of experimentation, combination and knowledge acquisition, they narrow the possibilities until arriving at final solution (see Fig. 5).

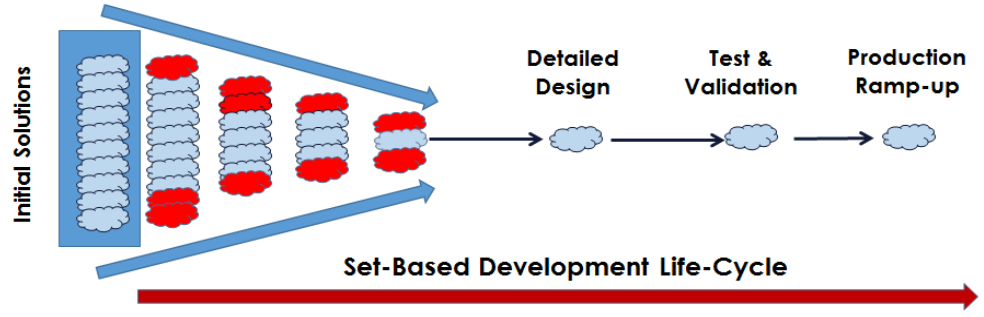

Fig. 5. Set-based development life-cycle

In order to the set-based development approach be successful, it relies on basic tools. As is usual in the lean philosophy, the tools should be simple and as possible rely on visual sense. Understanding and documenting technical knowledge in the case of the set-based approach is achieved in the forms of trade-off curves, checklists and limit curves. This form of representation naturally transfers tacit to explicit knowledge. Afterwards the approach integrates the knowledge through causal mapping for problem solving as depicted in Fig. 6. 


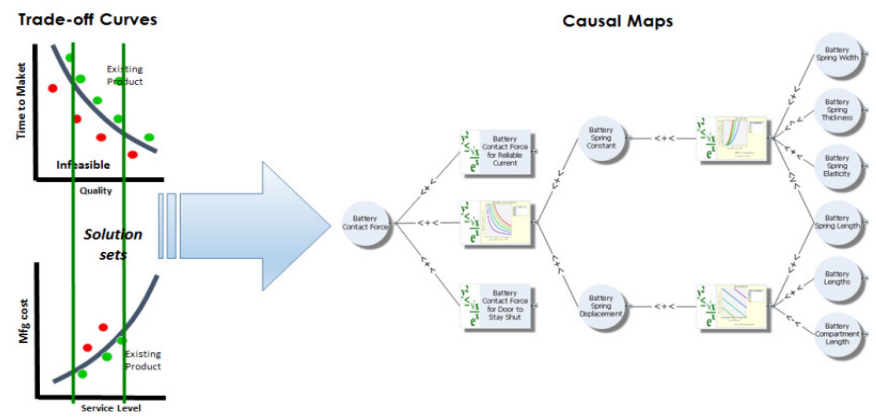

Fig. 6. Set-based development supporting tools

In summary, a set-based development approach enhances early and efficient learning so that enough information is attained before decision making. It requires collaborative learning and the involvement of many areas of expertise, but also the relevant stakeholders' commitment. In addition, by allowing delayed decisionmaking, until enough knowledge is acquired, enables wise decisions and not guessing. It also supports collaborative, converging decision-making by assuring that decisions in one area will not impact decisions on others areas.

Collaborative networks due to their intrinsic characteristics have immensely to benefit from this comprehensive approach proposed by the set-based development theory. The following chapter details how it is possible to apply set-based theory and methods in the collaborative networks environment through a customer-driven value chain framework.

\section{Customer-Driven Value Chain Framework}

The customer-driven value chain framework proposed aims to support companies in defining and forming collaborative networks for the demand of innovative and fashionable products with short life-cycles, small batch production and high configurability and parameterization. The framework is based on matching theoretical approaches from literature, namely the collaborative networks organizational paradigm and the lean approach of set-based design, but also, by matching practical requirements and constraints observed $R \& D$ industrial case projects namely on the textile, clothing and footwear industry (TCFI) sector.

The emerged needs from the analyzed business cases consider three different decision levels: strategic, tactical and operative. Figure 7 presents the overall conceptual view of this proposed framework mapping its decisional levels with the three framework structural dimensions considered, namely concepts, methods and tools. All these levels are instantiated along the dimensions and are embedded with the contributions from the collaborative networks paradigm and the lean set-based development system approach. 


\section{Customer-Driven Value Chain Framework}

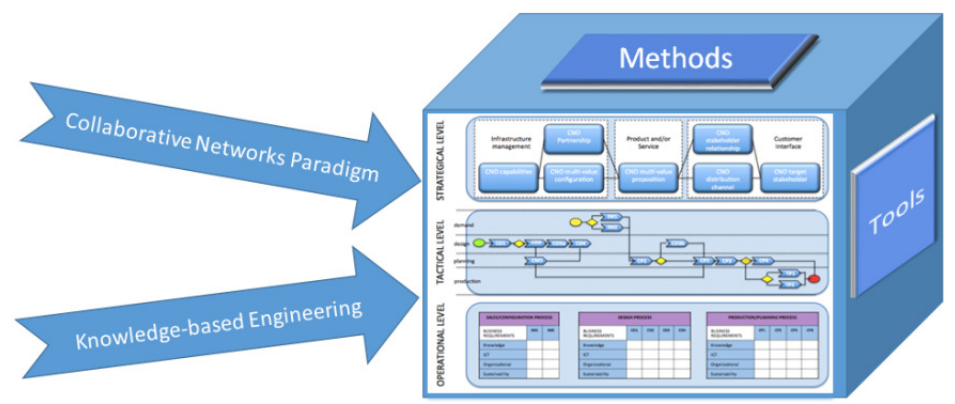

Fig. 7. Customer-driven value chain framework conceptual view

The customer-driven value chain framework proposal relies on two basic elements: methods and tools. The methods define guidelines which are instantiated though the definition of the business processes mainly through BPMN notation. On the other hand, in order to support the realization of the designed methods, specific ICT tools based mainly in web-technology are required and have been under design and implementation.

A critical element of the framework is related with the functional view of the value chain formation. Namely the partner search can occur in different phases of the network business scenarios namely at:

- Strategic level: during definition of the product portfolio when the manufacturer needs to select strategic partners which will support both the conception/design and the manufacturing of the products.

- Tactical level: collaboratively participating in the detailed product design and the matching production process design.

- Operational level: since a customer order is collected, it is necessary to select amongst the partners those who will be set off for that specific order.

For all of these three levels of collaborative work, different criteria and partner search capabilities shall be used, in order to ensure a comprehensive knowledge-based networked development engineering process.

In the case of the strategic level, the partner search is based on criteria for the identification and selection of partners based on a partner profile which summarizes the historical performance of the partner. The partner search at this early stage is useful in the definition of formal framework agreements. Namely, this formal agreements, bind partners in the commitment to reserve an amount of their production capacity for the production of a certain product along the production period and also participate in the early modular definition of products and respective interfaces. The selection of partners is based not only on the product characteristics but also on the historical performance of the partner in terms of quality, expertise, responsiveness and price. In this context, complementary indicators are flexibility and adaptability to requests from the focal company, which in summary is the ability to quickly reconfigure or set-up processes, to support new products variants or to vary quantities. 
Concerning the tactical level, the collaboration is tighten and comprehensive. Each partner make drafts, simulate and conduct tests of solutions. The proponent of business opportunity expects that the network partners explore the trade-offs among different product requirements, support decisions with test data and validate designs by delivering fully functional prototypes as early as possible in the process. In some cases, partners are asked to several alternative prototypes and their tradeoffs. While in traditional companies, a supplier of a particular component is picked at an early stage, using the set-based approach, network participants are asked to present alternatives solutions, present the feasibilities of the solutions, and develop sub-systems in parallel with the focus company designers.

Regarding the operational level, the identification and selection of partners participating on specific order requests is accomplished during the production phase among the partners already selected for the specific product during the strategic and tactical collaborative design phases. On the other hand, the selection of the manufacturing network members is based primarily on costs and capacity availability for the time period required by the customer. Product characteristics, quality and other parameters are previously defined during network formation.

In order to test and validate the concepts presented in this new holistic framework, a specific set of methods, tools and technologies were defined with the purpose to support the formation and the operation of collaborative networks. This framework supports the production of innovative and fashionable products by enabling collaborative product design, distributed manufacture and delivery of functional products aligned with the consumer needs. A crucial element devised to set up these services for the supply networks stakeholders is the Collaborative Portal (see Fig. 8).

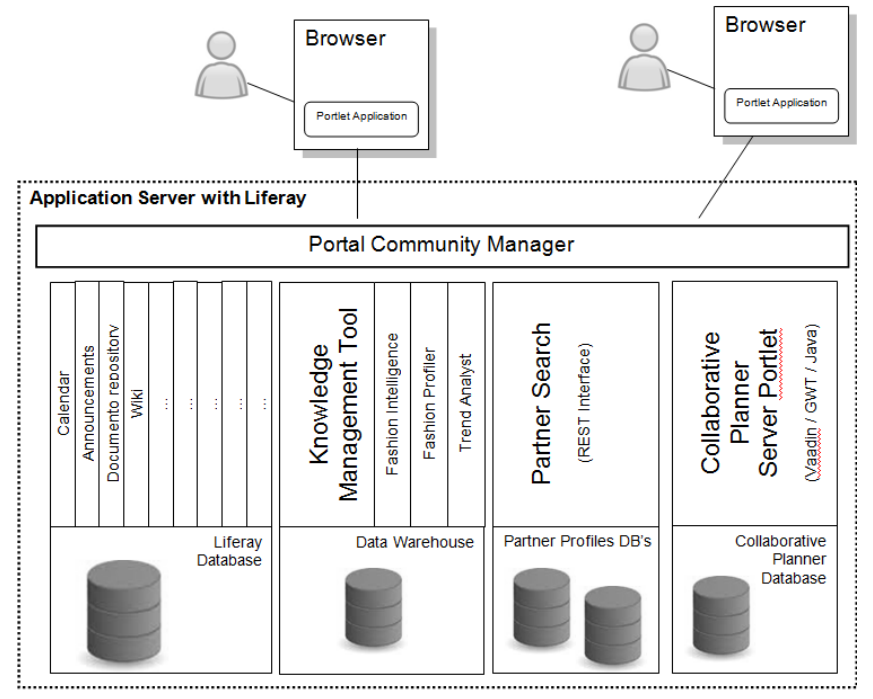

Fig. 8. Collaborative Portal Schema

The Collaborative Portal is a web-based front-end accessible through an Internet browser application. Using the Liferay web content management framework, the collaborative portal application server supports legacy integration and messaging with 
companies external applications such as MES and ERP's. Namely the collaborative portal supports the partner search functionalities for collaborative networks formation based on the following technological components and data:

- An ontology for the description of KPI concepts and relations;

- A repository of skills and performance data;

- An collaborative algorithm to perform search and matching for network formation;

- Integration of set-based knowledge approach through the support of trade-off curves and causal maps definition;

- Integration with the ERP databases for collection and synchronization of relevant data;

- A tool for collaborative production of customer orders.

In order to support the operation formation of the collaborative network, the collaborative algorithm used to search and matching for network formation abides to the following steps:

- A potential customer present a business opportunity to the company frontoffice (focal company that identifies the business opportunity and hosts the interaction with the customer);

- Following the definition of the key requirements on the required custom made product, the front-office starts an elicitation process for the selection of the core-partners that will participate in the conception and design activities and are committed in responding to the overall business opportunity. This selection is based on their identifiable competencies, historical performance and availability through a knowledge based engineering approach;

- After the new product design activities, the required list of operations in the manufacturing network are instantiated by the focal company and core partners, added with a preliminary sequence plan with time restrictions (start and finish dates), which take into account the due date specified by the customer and aggregated capacities defined on each partner's profile (again using a knowledge based engineering approach);

- At the beginning of the planning phase, the criteria for partner selection is defined and agreed by the core partners and subsequently will be used to assess the final solution. The criteria take into account historical performance, time period availability and partner expertise and knowledge. Through a knowledge based engineering approach the defined criteria is imported to the partner search module;

- Several partners are asked to bid for several operations. The selection of the partners for the network configuration is accomplished through a multi-criteria process according to the guidelines of the set-based approach. This leads to a "rough" manufacturing plan that the focal company proposes to all the partners of the newly formed collaborative manufacturing network.

- Afterwards the initially "rough" plan is decomposed in a set of partial requests for quotation on each operation for each partner. Subsequently the partner performs a local time-framed analysis of their local capacity and availability in order to assess if it is possible to respond to the proposed dates and lead time. 
Later a response quotation is created stating if the proposed plan is accepted with the cost of it, or replying with alternative solutions for the request both in terms of quantities or time constraints. Each response generates a possible plan that is assessed through a multi-criteria plan evaluation;

- The negotiation process continues until a satisfactory solution is achieved and a final manufacturing plan is accepted and implemented.

With this approach, it is addressed the role of the network ownership in an elegant way. Even though, the proposed approach relies on a centralized infrastructure when considering the information and communication technology elements, in reality, it promotes a decentralized approach on the formation and operation of the manufacturing network. This decentralized approach seeks to embody the concept of collaborative networks in which each partner is capable of proposing and participating actively on the characterization of each required product and/or operation, by working together with high degrees of integration and with matching goals.

In conclusion, through the development of the Collaborative Portal, the proposed framework offers a set of methods based on a web-based toolset designed to assist network managers and stakeholders in face of business opportunities to: create, update and reuse knowledge in development of new products using the set-based approach; to assist the configuration and the formation of collaborative networks by supporting the manufacturers in the identification and selection of the network partners; by supporting the operation of the network and the construction of manufacturing plans; and by assessing past and present network members performance through the computation of key performance indicators.

\section{Conclusions and Future Developments}

This work proposes a customer-driven value chain framework in order to create innovative collaborative environments which enable manufacturing companies to produce and supply small series of specialized and customized high value added products. The empirical origin of the framework empowers it to address the time to market issue for innovative and fashionable goods as a critical factor and guarantees full applicability of its guiding principles through the use of a lean inspired knowledge-based engineering approach.

In particular, the framework represents the translation of a methodology that can be instantiated to companies with the support of methods and tools for product codesign, collaborative process planning, networked manufacturing planning activities and assessment of partners' collaborative performance. The framework aspires to assist collaborative networks in understanding consumer needs, engage consumers in product co-design activities, assist in the creation and reuse of knowledge in the formation of the networks, encourage joint collaboration with network partners, and support innovative knowledge-based engineering design of new products through a lean inspired set-based approach.

The conceptual model of the framework, developed from previous and ongoing $\mathrm{R} \& \mathrm{D}$ projects with industrial partners has been applied to the real cases of TCFI 
industry. The instantiations made according to the three levels of the framework covered the definition of new business models and the description of the most relevant dimensions involved in its application concerning the strategy definition, the collaborative network formation, the product and process design process and the knowledge gathering.

Through the development of the collaborative portal, specifically a web-based toolset, it was possible to instantiate the framework concepts in a practical tool which supported the necessary mechanisms for network formation, the co-design approach, the knowledge gathering and reutilization, and the proficiency in designing and manufacturing of small lots of products. The fundamental objective of this collaborative portal was to offer an integrated set of collaborative services that support the network managers and stakeholders of innovative and/or fashionable product manufacturers with the necessary guidance and assistance to address the multitude of processes, activities, functions, decisions, relationships and interactions alongside with the products, services and information flows.

The proposed customer-driven value chain framework for small series production represents a contribution towards the definition of adequate business models addressing responsiveness and efficient use of knowledge on customized manufacturing and collaborative environments.

As future developments, it is intended for the research team to pursue the refinement of the proposed framework based on the contributions of the industrial users and the ongoing development of more efficient and reliable knowledge-based tools embed on the lean approach of set-based design in collaborative environments.

Acknowledgments. This work was financed by the Project "NORTE-07-0124FEDER-000057”, financed by the North Portugal Regional Operational Programme (ON.2 - O Novo Norte), under the NSRF, through the European Regional Development Fund, and by national funds, through the Portuguese funding agency, FCT - Fundação para a Ciência e a Tecnologia.

\section{References}

1. Sobek, D.K., A.C. Ward, and J.K. Liker, Toyota's principles of set-based concurrent engineering. Sloan management review, 1999. 40(2): p. 67-84.

2. Zangiacomi, A., et al., Reference Model Framework for Production of Small Series of Innovative and Fashionable Goods in Manufacturing Networks, in Advances in Sustainable and Competitive Manufacturing Systems. 2013, Springer. p. 1291-1303.

3. Trinkfass, G., The Innovation Spiral: launching new products in shorter time intervals. 2013: Springer-Verlag.

4. Camarinha-Matos, L.M. and H. Afsarmanesh. Collaborative networks: Value creation in a knowledge society. in PROLAMAT 2006, IFIP International Conference on Knowledge Enterprise - New Challenges. 2006. Shanghai, China, Springer.

5. Camarinha-Matos, L.M., X. Boucher, and H. Afsarmanesh, The Role of Collaborative Networks in Sustainability. Collaborative Networks for a Sustainable World, IFIP AICT Series 336/2010, Springer, pp. 1-16. 
6. Dyer, J.H. and H. Singh, The relational view: Cooperative strategy and sources of interorganizational competitive advantage. Academy of management review, 1998. 23(4): p. 660-679.

7. Grefen, P., et al., Dynamic business network process management in instant virtual enterprises. Computers in Industry, 2009. 60(2): p. 86-103.

8. Bastos, J., et al., Collaborative Networks Model for Clothing and Footwear Business Sector, in Collaborative Networks in the Internet of Services. 2012, Springer. p. 349-359.

9. Childerhouse, P., J. Aitken, and D.R. Towill, Analysis and design of focused demand chains. Journal of Operations Management, 2002. 20(6): p. 675-689.

10.de Treville, S., R.D. Shapiro, and A.-P. Hameri, From supply chain to demand chain: the role of lead time reduction in improving demand chain performance. Journal of Operations Management, 2004. 21(6): p. 613-627.

11.Piller, F.T. and M.M. Tseng, New directions for mass customization, in The Customer Centric Enterprise. 2003, Springer. p. 519-535.

12.Thatte, A.A., Competitive advantage of a firm through supply chain responsiveness and SCM practices. 2007, University of Toledo: Ohio.

13.Li, S., et al., The impact of supply chain management practices on competitive advantage and organizational performance. Omega, 2006. 34(2): p. 107-124.

14.Holweg, M., An investigation into supplier responsiveness: Empirical evidence from the automotive Industry. The Int. Journal of Logistics Management, 2005. 16(1): p. 96-119.

15.Ward, A.C. and D.K. Sobek II, Lean product and process development. 2014: Lean Enterprise Institute.

16.Ward, A., et al., Toyota, concurrent engineering, and set-based design. Ch, 1995. 8: p. $192-$ 216.

17.Liker, J.K., et al., Involving suppliers in product development in the United States and Japan: Evidence for set-based concurrent engineering. Engineering Management, IEEE Transactions on, 1996. 43(2): p. 165-178.

18.Inoue, M., et al., Collaborative engineering among designers with different preferences: Application of the preference set-based design to the design problem of an automotive front-side frame. Concurrent Engineering, 2013: p. 1063293 X13493447.

19.Kennedy, M.N. and K. Harmon, Ready, Set, Dominate: Implement Toyota's Set-based Learning For Developing Products And Nobody Can Catch You Author: Mich. 2008.

20.Romero, D. and A. Molina, Collaborative networked organisations and customer communities: value co-creation and co-innovation in the networking era. Production Planning \& Control, 2011. 22(5-6): p. 447-472.

21.Nambisan, S., Designing virtual customer environments for new product development: Toward a theory. Academy of Management Review, 2002. 27(3): p. 392-413.

22.Reimer, U., A. Margelisch, and M. Staudt, Eule: a knowledge-based system to support business processes. Knowledge-Based Systems, 2000. 13(5): p. 261-269.

23.Chu, M. and S. Tian;, Research on Knowledge Management of Collaborative Design. EBusiness and E-Government (ICEE), 2010 Int. Conference on, 2010: p. 1890 - 1893.

24.Sobek, D.K., Principles that shape product development systems: a Toyota-Chrysler comparison. 1997.

25.Kennedy, M.N. and A. Ward, Product development for the lean enterprise: why Toyota's system is four times more productive and how you can implement it. 2003: Oaklea Press Richmond, VA. 